\title{
SNOW-CORE ANALYSIS AT MID- AND HIGH ALTITUDE \\ IN THE SNOW-PACK
}

\author{
(Abstract) \\ by \\ Yves Page \\ (Department of Geography, University of Savoie, B.P. 1104, 73011 Chambéry Cédex, France)
}

\begin{abstract}
Since 1977, we have been studying the weather and climate of a mountain area, and particularly the winter snow-pack.

The area is situated in the French Alps, at an altitude of $1450-2500 \mathrm{~m}$. Since winter $1982-83$, we have been studying the snow-pack each week and every time we collected snow cores. We collected them at different test sites (area 1: $1850 \mathrm{~m} \mathrm{NW}$; area 2: $1800 \mathrm{~m} \mathrm{SE}$; area 3: $1600 \mathrm{~m}$ $\mathrm{NW}$; area 4: $2000 \mathrm{~m}$ ).

The following parameters were collected at the test sites on a continuous basis throughout the winter: new and total snow depth, wind direction and precipitation (solid and liquid), snow-water equivalent (precipitation and total snow
\end{abstract}

depth), standard snow profiles, and structure of the snowpack.

After data analysis, many different questions were investigated, in two respects:

(1) Analytical techniques: problems of sampling snow cores (transport, conservation, evolution), and analysis of the micro-structure of the different snow layers in correlation with the macro-structure of the snow-pack.

(2) Results and interpretations: do changes in the structure (macro- and micro-structure) of the snow cores take place during their conservation? Can we consider snow cores as preserving the record of the winter climate (precipitation, chemical pollution)?

(3) Data archive: Constitution of snow-core data archive, in relation to the climatology of the area.

\section{ON THE RELATIONSHIP BETWEEN ${ }^{18} 0 /{ }^{16} 0$ RATIOS OF PRECIPITATION AND CLIMATE}

\author{
by
}

U. Siegenthaler

(Universität Bern, Physikalisches Institut, $\mathrm{CH}-3012$ Bern, Sidlerstraße 5, Switzerland)

\begin{abstract}
A quantitative interpretation of oxygen-isotope data in ice cores in terms of climate has so far been hampered by the lack of a quantitative understanding of the processes which determine the isotopic composition of precipitation. Dansgaard (1964) has demonstrated that observed relations between ${ }^{18} \mathrm{O} /{ }^{16} \mathrm{O}$ and temperature can be explained reasonably well by the Rayleigh condensation model. This model is re-interpreted by noting that it predicts a dependence of the ${ }^{18} \mathrm{O} /{ }^{16} \mathrm{O}$ ratio on the water-vapour mixing ratio in the atmosphere. The relationship between the monthly data from different European stations and the water-vapour mixing ratio agrees remarkably well with the Rayleigh model. Data from Greenland snow show good correlation with the following parameters: mean annual
\end{abstract}

temperature $\mathrm{T}_{\mathrm{a}}$, the water-vapour mixing ratio corresponding to $\mathrm{T}_{\mathrm{a}}$, and the accumulation rate. These correlations will be discussed in terms of the Rayleigh model and of the underlying physical processes. The correlation between ${ }^{18} \mathrm{O} /{ }^{16} \mathrm{O}$ ratios and the accumulation rate allows us to estimate the latter during the ice age. The change in the accumulation rate between the ice age and postglacial time can also be estimated from the chemical composition or the ${ }^{10} \mathrm{Be}$ concentration. The different results will be compared.

\section{REFERENCE}

Dansgaard W 1964 Stable isotopes in precipitation. Tellus 16(4): $436-468$ 